\title{
Mitral valve Replacement in a 4 yrs old Child: First Time in Bangladesh
}

\author{
MR Hoque, MSA Sunny, MM Rahman \\ Department of Cardiac Surgery, Bangabandhu Sheikh Mujib Medical University, Dhaka.
}

\begin{abstract}
:
Key Words : Congenital heart

Congenital mitral valve incompetence is a rare and complex congenital heart disease in children. We report, a case of a 4-year-old child admitted to hospital with fever, dyspnea on exertion or feeding and repeated respiratory infection for last 3 years. The transthoracic echocardiogram revealed grossly dilated left atrium and left ventricle and severe mitral regurgitation due to cleft in anterior mitral leaflet. Per-operatively mitral valve annulus was found very much dilated; leaflet thinned out and rudimentary posterior mitral leaflet. Morphology of mitral valve was totally distorted, leaflets were diminutive and beyond repairable. Mitral valve replacement was done with $25 \mathrm{~mm}$ Edward Life Science porcine tissue heart valve with total preservation of subvalvular structure and the patient showed dramatic symptomatic improvement and later follow up revealed good LV function with alleviation of symptoms. This is a rare and unusual case of congenital mitral valve disease with better prognosis after surgical replacement with tissue valve.
\end{abstract}

(Cardiovasc. j. 2014; 6(2): 167-169)

\section{Introduction:}

Congenital malformations of mitral valve are rare, complex and frequently associated with other congenital malformations of the heart or the aorta that may hide or be hidden by the valve malformation. ${ }^{1}$ Congenital mitral incompetence is even rarer. ${ }^{2}$ Congenital mitral valve incompetence may lead to repeated pulmonary infections, cardiac failure and eventually failure to thrive. In practice, repeated episodes of cardiac failure and progressive enlargement of systolic diameter indicates a deterioration of systolic function. This must be recognized and should indicate an operation, whatever the age. ${ }^{1}$ Despite improving surgical techniques, treatment of heart valve disease in children remains controversial. ${ }^{3}$ Growth of the child and adequate anticoagulation level are the main concerns when valve replacement is preferred in the pediatric age. ${ }^{3}$ In patient with congenital mitral valve disease, reconstructive surgery is the primary goal. However, in cases with severely dysplastic valves or failed repair, mitral valve replacement is the only option. ${ }^{4}$

\section{Case report:}

A 4 years old child admitted on Metropolitan medical centre, Dhaka, Bangladesh with the complaints of fever, dyspnea on exertion or feeding and repeated respiratory infection requiring repeated hospitalization for last 3 years. Physical examination revealed a regular pulse 100 beat/min, blood pressure 100/60 mm of $\mathrm{Hg}$, and bibasal crackles on chest auscultation. Her first heart sound was developed in mitral area and second heart sound was normal but there is a blowing pan systolic murmur present at the apex. Electrocardiogram showed heart rate $100 / \mathrm{min}$, regular with feature of left atrial enlargement and left ventricular hypertrophy. The chest X-ray showed pulmonary congestion and a moderate cardiac enlargement. Color Doppler echocardiogram revealed grossly dilated left atrium and left ventricle, severe mitral regurgitation due to cleft in anterior mitral leaflet (Figure-1) and PASP $86 \mathrm{~mm} \mathrm{Hg}$.

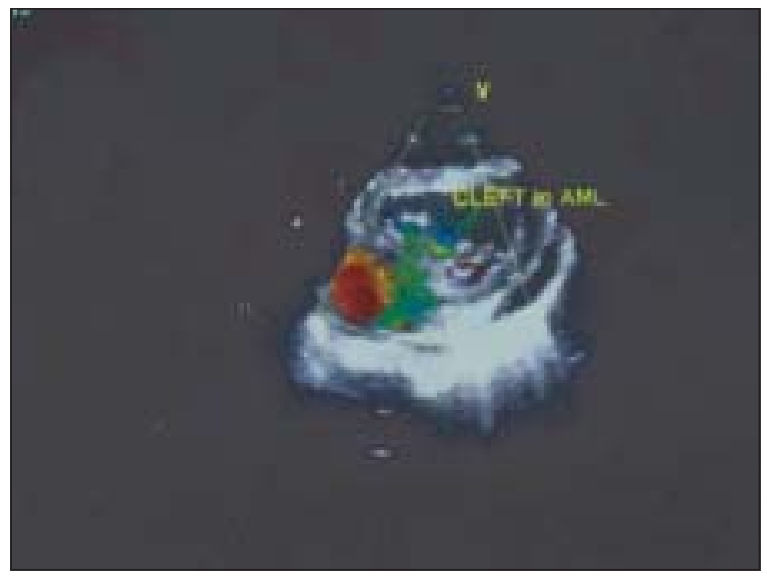

Fig.-1: Cleft in anterior mitral leaflet (echocardiographic view) 


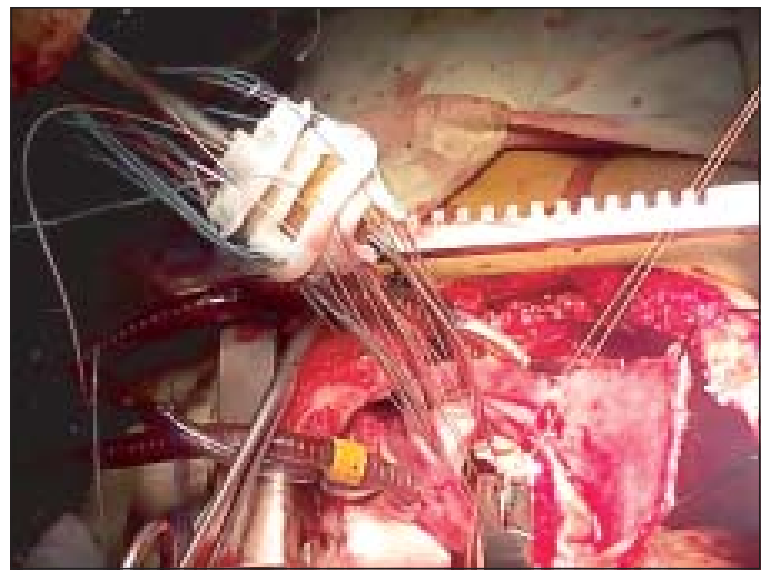

Fig.-2: Mitral Valve Replacement with Tissue Valve (25mm Edward life science porcine Valve).

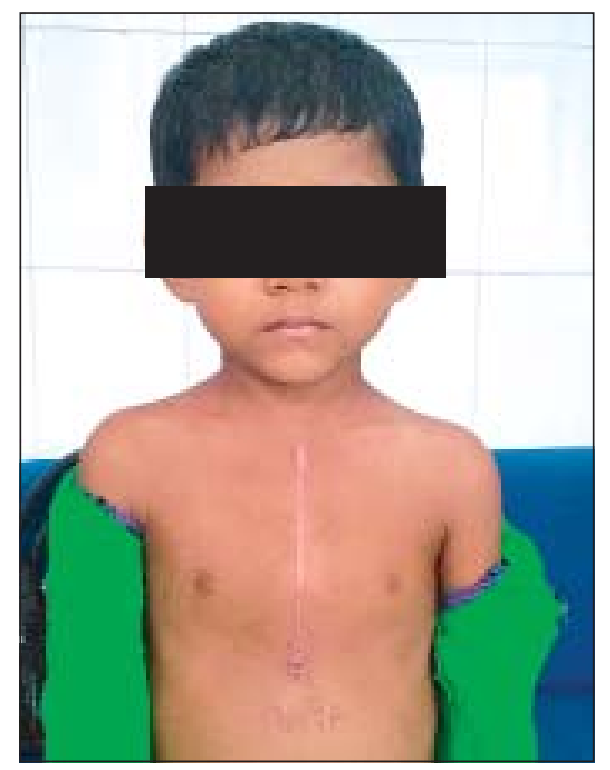

Fig.-3: Patient on subsequent follow up.

Patient was operated on 18.09.2013. Under general anesthesia with all aseptic precautions standard median sternotomy was done. After thymus dissection pericardiotomy was done. Cardiopulmonary bypass was established with bicaval cannulation with aortic cannulation. Heart was arrested by giving crossclamp and antegrade cardioplegia under mild hypothermia $\left(32^{0} \mathrm{C}\right)$. Left artiotomy done. Mitral valve annulus was very much dilated; leaflets were thinned out, rudimentary posterior mitral leaflet. Morphology of mitral valve totally distorted and it was beyond repairable. Mitral valve replacement was done with $25 \mathrm{~mm}$ Edward Life Science porcine tissue heart valve with total preservation of subvalvular structure (figure-2).
A vent was given through right superior pulmonary vein to left atrium. Left atriotomy closed. Patient weaned from cardiopulmonary bypass without any difficulty. X-clamp time was $28 \mathrm{~min}$ and Total bypass time was $60 \mathrm{~min}$. After achieving proper haemostasis, chest was closed leaving one mediastinal drain tube (retrosternal $24 \mathrm{Fr}$ ) attached under water seal drain bag. The patient was shifted to the ICU with minimum inotropic support. Patient was extubated on the same day, shifted to general word on $3^{\text {rd }}$ POD and discharged home on $10^{\text {th }}$ POD with advice of taking oral anticoagulant Warfarin Sodium $1 \mathrm{mg}$ daily only for 3 months followed by antiplatlet therapy. Patient remains asymptomatic in the subsequent follow up (figure- 3) and leading to a normal life.

\section{Discussion:}

Isolated congenital mitral regurgitation is caused by defects in the leaflet tissue (isolated cleft), absent or redundant chordate tendineae and abnormal size or location of papillary muscle. ${ }^{5}$ Our patient have congenital mitral regurgitation due to cleft in anterior mitral leaflet with diminutive mitral leaflet tissue.

At all ages, patients with mitral regurgitation present with various degrees of failure to thrive, dyspnea on feeding or exertion. An enlarged left ventricular impulse may be present and a highfrequency, high-intensity holosystolic murmur is heard at the apex extending into the axillae. ${ }^{6}$

Isolated congenital mitral regurgitation is often only moderate in severity in early life and about half of the patient with it do not show development of important symptoms or come to operation until older than about age 5 years. ${ }^{7}$ The sign and symptom of our 4 years old patient started from 1 year and severity of symptoms was gradually increasing with her age.

The electrocardiogram shows left atrial and left ventricular enlargement in patient with mitral regurgitation and chest radiography demonstrate cardiomegaly. ${ }^{6}$ Our patient also had left atrial and left ventricular enlargement on electrocardiogram and cardiomegaly on chest X-ray.

Transthoracic echocardiography provides nonspecific evidence as to enlargement of left 
ventricle, left atrium and right ventricle. ${ }^{2}$ Real time 3-dimentional echocardiography demonstrated the cleft with its wide and depth, the extent of cleft edge fibrosis and retraction, and the presence of accessory chordae and their attachment to the septum. ${ }^{8}$ Our patient have only cleft on anterior mitral leaflet with rudimentary posterior mitral leaflets.

Mitral valve replacement might be necessary in children with extremely dysplastic valves and severe hemodynamic impairment or after failed repair. ${ }^{9}$ Mortality and mitral reoperation are common after mitral valve replacement in children and outcomes can be predicted based on patient's age and other associated factors. ${ }^{10}$ A study showed that bileaflet prosthesis larger than $23 \mathrm{~mm}$ have the lowest operative risk. ${ }^{11}$ Valve related complications are thromboembolism, hemorrhage, structural deterioration and non-structural dysfunction. A study done on comparing on 24 children on 2 to 18 years of age who have received mechanical valve compared with 24 children who received porcine. Major complications were seen in 50 percent of mechanical valve group and 13 percent of porcine valve group. Superiority of tissue heart valve on children is established. ${ }^{12}$ A study on 64 children suggested that despite the disappointment occurrence of premature tissue valve failure in young population, valve replacement in children currently safer. ${ }^{13}$ Our patient has extreme dysplastic mitral valve and cleft anterior mitral leaflet and rudimentary posterior mitral leaflet with significant hemodynamic impairment. So, repair was not feasible for her. We replaced the mitral valve with $25 \mathrm{~mm}$ porcine tissue heart valve without any post-operative complication which supports these data.

A study showed that the durability of bioprosthetic heart valve is severely limited by early calcification and therefore mechanical heart valves are the preferred option, albeit at the expense of lifelong anticoagulation. ${ }^{14}$ Now a days, because of better anticalcific treatment, the durability of tissue valve is increased. ${ }^{15}$ So, considering the difficulty in maintaining anticoagulation in remote rural area of Bangladesh tissue heart valve was preferred in children.

\section{Reference:}

1. Carpentier A, Brizard C. Congenital malformation of Mitral valve. In: Stark J, Level MD,Tsang VT. Eds. Surgery for congenital heart defects. West Sussex: John Wiley \& Sons Ltd, 2006: 577-590.

2. Smallhorn JE, Anderson RH. Anomalies of the morphologically Mitral valve. In: Anderson RH, Baker EJ, Penny D, Redington AN, Rigby ML, Warnovsky G. Eds. Paediatric Cardiology. Pholadelphia: Churchill Livingstone Elsevier, 2010: 731-751.

3. Vosa C, Renzulli A, Lombardi PF, Damiani G. Mechanical valve replacement under 12 years of age: 15 years of experience. The Journal of Heart Valve Disease 1995; 4: 279-283.

4. Gunther T, Mazzitelli D, Schreiber C, et al. Mitral-valve replacement in children under 6 years of age. Eur $J$ Cardiothorac Surg 2000; 17: 426-430.

5. Carpentier A, Bronchini B, Cour JC, et al. Conginital malformation of the mitral valve in children.Pathology \& Surgical treatment. J Thorac Cardiovasc Sur 1976; 72: 854-856.

6. Brizard CP. Congenital Anomalies of the Mitral Valve. In: Sellke FW, Nido PDJ, Swanson SJ. Sabiston \& Spencer Surgery of the Chest. Pholadelphia: Saunders Elsevier, 2010: 2015-2025.

7. Carabello BA, Nolan SP, McGuire LB. Long-term results of valve repair in children with mitral incompetence. Circulation 1986; 74: 1104-1106.

8. Kuperstein R, Feinberg MS, Carasso S, Gilman S, Dror Z, Di Segni E. The added value of real-time 3-dimentional echocardiography in the diagnosis of isolated cleft mitral valve in adults. J Am Soc Echocardiogr 2000; 19: 811-814.

9. Fatemeh K, Rui C, Chistopher A, et al. Outcomes of mitral valve replacement in children: A competing-risks analysis. J Thorac Cardiovasc Sur 2004; 128: 703-709.

10. Bahaaldin A, Cedric M, Ahmadi MA, et al. Outcomes and associated risk factors for mitral valve replacement in children. Eur J Cardiothorac Surg 2011; 40: 543-551.

11. Brown JW, Foire AC, Ruzmelov M, et al. Evolution of mitral valve replacement in children: A 40-year experience. Ann Thorac Surg 2012; 93: 626-633.

12. Sade RM, Ballenger JF, Hohn AR, et al. Cardiac valve replacement in children: comparison of tissue with mechanical prosthesis. J Thorac Cardiovasc Sur 1979; 78: 123-127.

13. Woods A, Vagus J, Berri G, et al. Antithrombotic therapy in children and adolescents. Thrombosis Research 1986; 42: 289-301.

14. Doorn CV, Yates R, Tsang V, Delevel M, Elliot M. Mitral valve replacement in children: mortality, morbidity, and haemodynamic status up to medium term follow up. Heart 2000; 84: 636-642.

15. Gardner TJ, Roland JM, Neill CA, Danahoo JS.Valve replacement in children. A fifteen-year prospective. $J$ Thorac Cardiovasc Sur 1982; 83: 178-183. 